Studies in African Linguistics

Volume 41, Number 2, 2012

\title{
BONDU-SO VOWEL HARMONY: A DESCRIPTIVE ANALYSIS WITH THEORETICAL IMPLICATIONS
}

\author{
Abbie Hantgan \& Stuart Davis \\ Indiana University
}

\begin{abstract}
This paper provides a descriptive analysis of the [ATR] vowel harmony system of Bondu-so (Dogon, Mali), a previously undocumented language. Data come from fieldwork and have not yet been published. While Bondu-so has seven surface vowels, namely, two [+ATR, +high] vowels ([i], [u]), a [-ATR +low] vowel [a] and a $[ \pm \mathrm{ATR}]$ contrast in the mid vowels with front $[\mathrm{e}] /[\varepsilon]$ and back $[\mathrm{o}] /[0]$, there is evidence for a more abstract vowel system phonologically consisting of ten vowels with $[ \pm$ ATR] contrasts with all vowel heights. Further, the language shows a threeway contrast with respect to the feature [ATR] on suffixal vowels: some suffixal vowels act as [+ATR] dominant, spreading their [+ATR] feature onto the root; other suffixes act as [-ATR] dominant, spreading [-ATR] onto the root, and still other suffixes have vowels unspecified for [ATR] receiving their $[ \pm A T R]$ feature by rightward spreading of the $[ \pm \mathrm{ATR}]$ value of the root vowel. We offer an autosegmental analysis and then discuss the theoretical implications of such an analysis. These implications include the ternary use of [ATR], the issue of phonological versus morphological harmony, the relationship between vowel inventories and [ATR] harmony systems, and the question of abstractness in phonology.
\end{abstract}

\section{Introduction}

This paper examines the complex $[ \pm \mathrm{ATR}]$ vowel harmony patterns in Bondu-so [bòndúsó], (specifically the closely related dialects Kindige [kìndìgé] and Najamba [nàdzàmbá]), a Dogon language spoken in Central-Eastern Mali. The data are from the first author's familiarity with the language since learning it as a Peace Corps volunteer and continuing fieldwork done in Mali with two Kindige speakers by the first author in 2010 and in Burkina Faso with another Kindige speaker in 2012. Lexical items which come from Najamba are found in (Heath 2011) and confirmed with the Kindige speakers. ${ }^{1}$ In addition to all of the

\footnotetext{
${ }^{1}$ This research was funded through National Science Foundation grant BCS-0537435, "Dogon languages of Mali" of which Jeffrey Heath is the principle investigator. We are indebted to the patient consultants who provided the data for this research, Hama and Issa Sangalbah, and to Jeffrey Heath for his
} 
lexical items and acoustic measurements used for this study, a preliminary description of the phonology and morphology of Kindige is available at the Dogon languages project website, http://dogonlanguages.org/.

We maintain the vowel harmony patterns in Bondu-so reflect an abstract phonemic vowel system. We argue that the language has a ten-vowel system with high, low and [ \pm ATR] contrasts underlyingly; however, only seven distinct vowel qualities surface: [i e $\varepsilon$ a $\circ$ o u ], with the $[ \pm \mathrm{ATR}]$ contrast realized only on the mid vowels. High vowels are realized as [+ATR] and the low vowel as [-ATR] due to phonetically grounded constraints banning [ATR] high vowels and [+ATR] low vowels (Archangeli \& Pulleyblank 1994). We present evidence for this abstract analysis from the different types of $[ \pm A T R]$ vowel harmony that occur within the language.

We present an analysis that proposes an underlying set of ten vowels for Bondu-so, although future studies could include additional Dogon languages. Speaking purely from a data viewpoint, all the Dogon languages thus far studied have stems with [ATR] vowel harmony that could be analyzed with the same underlying ten vowels that we propose for Bondu-so since high and low vowels appear with both [-ATR] and [+ATR] suffixes. Heath (n.d.), though, considers [i u] as analytically 'extra-harmonic' or neutral, noting that [i u] may pattern like $\left[\begin{array}{ll}\varepsilon & \text { o}\end{array}\right]$ respectively in all studied Dogon languages. He states, "We have not observed any audible phonetic differences between two /i/ vowels or two /u/ vowels, so the distinction (in this analysis) would be covert." However, the details of his suggested analysis have not been worked out for the various constructions as we do here for Bondu-so.

Our analysis maintains that the initial vowel of Bondu-so content words is specified for a [+ATR] or [-ATR] feature which spreads to suffixes unspecified for the feature $[ \pm A T R]$. (Note that Dogon languages do not have prefixes.) However, there are suffixes which are specified for a $[ \pm$ ATR $]$ feature. Such suffixes spread their $[ \pm$ ATR $]$ feature onto the root word in a feature-changing manner. Since both $[+$ ATR $]$ and $[-A T R]$ can spread from either the root initial vowel or from a suffix specified for a feature value of [ATR], there is no consistency as to whether [+ATR] or [-ATR] should be an underspecified feature. Based on these facts, we propose there is a three-way distinction for [ATR] among suffixes: [+ATR], [-ATR], and unspecified for [ATR]. Moreover, these patterns hold for both nouns and verbs, although most of our examples come from verb stems. Evidence for the abstract phonemic vowel system comes from the observation that certain roots with high vowels trigger [-ATR] harmony on the suffix although the high vowel of such roots surface as [+ATR]. Similarly,

assistance with this study. We also thank Michael Becker, Daniel Dinnsen, Tracy Alan Hall, Larry Hyman, Andrew Nevins, Sharon Rose, and Rachel Walker for discussion on various aspects of this paper and the audiences at Mid-Phon 17 , the $86^{\text {th }}$ LSA meeting, the $43^{\text {rd }}$ ACAL, and the $20^{\text {th }}$ Manchester Phonology Meeting for their questions on preliminary versions of this paper. We further acknowledge the editor and two anonymous reviewers for their detailed comments. 
some roots with initial low vowels trigger [+ATR] harmony although such low vowels are not perceptually distinct from the low vowel roots that trigger [-ATR] harmony. Further, we will argue against a floating feature analysis of roots since certain suffixes have the property of introducing a floating [ATR] feature that is realized on the root and not on the suffix sponsoring the feature. This suggests that the constraint preventing the floating feature from being realized on their sponsors is high-ranked in Bondu-so. (See Wolf 2007 for discussion of this constraint.) Thus, we will maintain that the vowel harmony system supports an underlying vowel system of 10 vowels, /i i $\varepsilon$ e a a $\rho$ o $v \mathrm{u} /$, in which there is a $[ \pm \mathrm{ATR}]$ contrast on all vowel heights. The contrast is neutralized on the surface for high and low vowels.

Although we do not present an optimality-theoretic analysis at this time, in order to account for the neutralization of underlying $[-\mathrm{ATR},+\mathrm{HI}]$ vowels to $[+\mathrm{ATR}]$ we refer to the grounded constraint, * $[-\mathrm{ATR},+\mathrm{HI}]$, which bans high vowels with [-ATR]. And in order to account for the neutralization of the $[+\mathrm{ATR},+\mathrm{LO}]$ vowels to $[-\mathrm{ATR}]$ we invoke the grounded constraint *[+ATR, $+\mathrm{LO}]$, which disallows low vowels with the [+ATR] feature in phonetic form. These constraints are based on the typologically and articulatorily grounded generalizations discussed by Archangeli \& Pulleyblank (1994), and references therein, who show that these feature combinations, $[-\mathrm{ATR},+\mathrm{HI}]$ and $[+\mathrm{ATR},+\mathrm{LO}]$, are acoustically antagonistic and are avoided in many languages.

This paper is organized as follows: Section 2 presents the data and analyses of a range of $[ \pm$ ATR] harmony phenomena in Bondu-so. The data will be presented in terms of complexity with less complex cases of harmony being discussed before more complex cases. We first demonstrate vowel harmony patterns among verb stems in the perfective $\left[3^{\text {rd }}\right.$ person singular]. These stems provide evidence for the underlying contrast between [+ATR] and [-ATR] vowels of all heights. Next, we discuss root-controlled, $[ \pm \mathrm{ATR}]$ harmony among one class of plural nouns. Then, we show data illustrating suffix-controlled [+ATR] and [-ATR] harmony in infinitival forms, the mediopassive, and in a different class of plural stems, respectively. We then introduce a more complex set of data involving the $2^{\text {nd }}$ person singular imperative, which we propose introduces a floating [+ATR] feature, in addition to [ $\left.{ }^{\mathrm{A} A T R}\right]$ feature spreading from the root. These data demonstrate that neither [+ATR] nor [-ATR] can act as a default feature since both are active features in the language. The final set of data illustrates the imperfective, which integrates the aforementioned types of vowel harmony through the interaction between the root and two suffixes, namely, the suffix marking the imperfective aspect and the suffix marking person. Section 3 discusses some theoretical consequences of the Bondu-so data. These include issues related to underspecification and active features (Archangeli \& Pulleyblank 1989, Noske 2000, Bakovic 2000), matters related to floating features (Wolf 2007; Finley 2009), the relationship between [ \pm ATR] harmony and the nature of the vowel inventory (Casali 2008), and the abstract nature of our analysis with discussion on preliminary work regarding the phonetics of Bondu-so vowels. We conclude by discussing some directions for future research. 


\section{Data and Analyses of Harmony Processes}

In this section we introduce a wide variety of vowel harmony process in Bondu-so including both root and suffix controlled $[ \pm \mathrm{ATR}]$ harmony. In addition to the data presented here, the reader is encouraged to reference the comprehensive presentation and description of the phonology and morphology of Kindige, and the grammatical description of Najamba, drafts of which are found at http://dogonlanguages.org/. First, in analyzing the data, we maintain that there are 10 phonemic vowels with a contrast of $[ \pm$ ATR $]$ for each vowel height, although on the surface the contrast is realized only on the mid vowels. Also, we maintain that in Bondu-so neither [+ATR] nor [-ATR] acts as a default feature. We present data going from least complex to most complex instantiations of vowel harmony.

2.1 Root-controlled [ \pm ATR] Harmony: Perfective. Root-controlled vowel harmony in Bondu-so can be found with both verbs and nouns. In our analysis of Bondu-so, the initial vowels of all roots are specified for a $[ \pm \mathrm{ATR}]$ feature. The feature spreads rightward. The vast majority of lexical roots are monosyllabic. Longer roots do not show clear cases of tongue root disharmony. For example, $[+\mathrm{ATR}]$ and $[-\mathrm{ATR}]$ mid vowels do not co-occur. Although we do not analyze longer roots here, our spreading analysis is consistent with the vowel co-occurrences in such roots, since, as noted, [+ATR] and [-ATR] mid vowels do not appear together in the same root. ${ }^{2}$ In the clearest cases of root-controlled harmony, suffixes are unspecified for $[ \pm \mathrm{ATR}]$ so that the $[ \pm \mathrm{ATR}]$ feature of the root spreads. In this subsection we consider the perfective, and in section 2.2 a specific noun class.

The data in (1) show verbs in the perfective form $\left[3^{\text {rd }}\right.$ person singular]. Note that most verb roots in Bondu-so are monosyllabic and consonant-final. The perfective suffix displays two allomorphs: [-è] in the left column and $[-\grave{\varepsilon}]$ in the right column of (1). ${ }^{3}$ (A grave accent indicates low tone and the acute accent indicates high tone. Tone quality does not affect vowel harmony processes. We observe that some morphological classes display specific tone patterns. For example, as shown in (1), perfective forms always surface with low tone. The tonal analysis is beyond the scope of this paper.)

\footnotetext{
${ }^{2}$ We assume that in such bisyllabic roots that the second vowel receives its [ATR] value from spreading from the first vowel. In Bondu-so, roots always occur with a suffix and never stand alone.

${ }^{3}$ The perfective suffix is represented here as a short vowel as it surfaces in Najamba; it is long in Kindige.
} 
(1) Root-controlled [ \pm ATR] harmony: Perfective

\begin{tabular}{|c|c|c|c|c|}
\hline Stem [+ATR] & Gloss & & Stem [-ATR] & Gloss \\
\hline [nèmbìl-è] & s/he begged & f. & {$[\mathrm{k} \dot{\varepsilon} \mathrm{d}-\hat{\varepsilon}]$} & s/he cut \\
\hline [nòj-è] & $\mathrm{s} /$ he slept & g. & [dòg- $-\grave{\varepsilon}]$ & s/he left (it) \\
\hline [bìj-è] & $\mathrm{s} /$ he laid down & h. & [gìj-ì] & s/he killed \\
\hline [sùg-è] & $\mathrm{s} /$ he went down & i. & [dzùg-ì ] & $\mathrm{s} /$ he recognized \\
\hline [bàr-è] & s/he helped & j. & 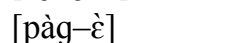 & $\mathrm{s} / \mathrm{he}$ tied \\
\hline
\end{tabular}

As shown in the examples in (1a-b), the [+ATR] variant of the perfective suffix follows a root which contains a mid [+ATR] vowel. The examples in (1f-g) illustrate that the $[-\mathrm{ATR}]$ allomorph of the suffix follows a root which contains a mid [-ATR] vowel. Examples (1c-d) show that the two $[+\mathrm{ATR},+\mathrm{HI}]$ vowels $([\mathrm{i}],[\mathrm{u}])$, do not contrast phonetically with the counterparts in $(1 \mathrm{~h}-\mathrm{i})$; nonetheless, the comparison of $(1 \mathrm{c}-\mathrm{d})$ with $(1 \mathrm{~h}-\mathrm{i})$ indicates the perfective suffix alternates between the two $[ \pm A T R]$ values of the mid vowel suffix. These examples illustrate that in some roots, $(1 \mathrm{~h}-\mathrm{i})$, high vowels pattern as [-ATR] even though they surface phonetically as $[+$ ATR]. Speakers do not perceive a difference in a high vowel that triggers [+ATR] harmony as in (1c-d) from one that triggers [-ATR] harmony as in (1h-i). The remaining verbs in (1) show that the $[-\mathrm{ATR},+\mathrm{LO}]$ vowel feature on the root in (1e) and (1j), has the expected [-ATR] value on the suffix in (1j), but has an unanticipated [+ATR] value on the suffix in (1e). In other words, the root vowel in (1e) acts as if it is underlyingly $[+\mathrm{ATR}]$ even though it surfaces as $[-\mathrm{ATR}] .^{4}$

Based on the data in (1) we posit the following underlying forms represented in (2). Here we propose that there is a phonemic contrast for the $[ \pm \mathrm{ATR}]$ feature for all vowel heights, but the high and low vowels neutralize so that the high vowels in (2h-i) surface as [+ATR] (as in $(1 \mathrm{~h}-\mathrm{i})$ ), and the low vowel in (2e) surfaces as $[-\mathrm{ATR}]$ as in (1e). The $[-\mathrm{ATR},+\mathrm{HI}]$ root vowels in (1h-i) surface at [+ATR] because they are subject to the phonetically grounded feature co-occurrence constraint *[-ATR, $+\mathrm{HI}]$ (Archangeli \& Pulleyblank 1994). The $[+\mathrm{ATR},+\mathrm{LO}]$ root vowel in $(1 \mathrm{e})$ surfaces as $[-\mathrm{ATR}]$ because of the phonetically grounded feature co-occurrence constraint $*[+\mathrm{ATR},+\mathrm{LO}]$.

\footnotetext{
${ }^{4}$ In light of Gick et al. (2006), an important question concerns the phonetics of the two classes of low vowels (1e vs. 1j) and the two classes of high vowels (1c, d vs. 1h, i). As we will discuss in Section 3.4, there is some preliminary acoustic phonetic evidence that there is no difference between the two classes of high and low vowels.
} 
(2) Proposed Underlying Root Forms

\begin{tabular}{|c|c|c|c|c|c|}
\hline & Stem [+ATR] & Gloss & & Stem [-ATR] & Gloss \\
\hline a. & /nembil/ & beg & f. & $/ \mathrm{k} \varepsilon \mathrm{d} / \mathrm{I}$ & cut \\
\hline b. & /noj/ & sleep & g. & /dog/ & leave it \\
\hline c. & /bij/ & lie down & h. & /gij/ & kill \\
\hline d. & /sug/ & go down & i. & /dzog/ & recognize \\
\hline e. & /bąr/ & help & j. & /pag/ & tie \\
\hline
\end{tabular}

In our analysis of the Bondu-so vowel harmony data in (1), the initial vowel of Bondu-so verb roots is specified underlyingly for a $[+$ ATR $]$ or $[-$ ATR $]$ feature. The vowels in the roots in the left column of the data set in (1) have [+ATR] and those in the right columns have [ATR] values underlyingly. This is shown in (2). We claim that the only vowel underspecified for the feature [ATR] among the data in (1) is the perfective $\left[3^{\text {rd }}\right.$ person singular] suffix. The vowel of the perfective aspect $\left[3^{\text {rd }}\right.$ person singular] suffix is mid and front but unspecified for $[ \pm \mathrm{ATR}]$, and can be represented as $/-\mathrm{E} /$. The suffix obtains its surface $[ \pm \mathrm{ATR}]$ quality by spreading from the root vowel. This analysis is represented autosegmentally in (3).

(3) Autosegmental Analysis of Harmony Perfective $\left[3^{\text {rd }}\right.$ person singular] Stems

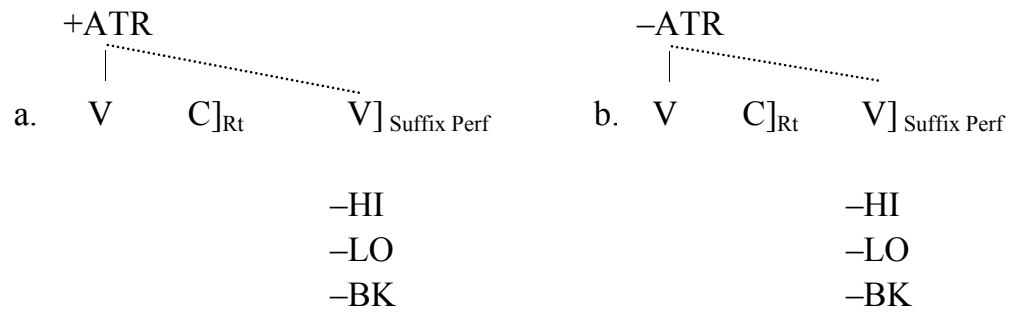

As shown in (3a-b), the $[ \pm$ ATR $]$ value of the initial vowel of the root spreads to the perfective suffix, which is crucially specified for height and backness but not [ATR]. In (4) we provide the derivations of three words to further exemplify our analysis. 
(4) Derivational Analysis of Harmony Perfective [ $3^{\text {rd }}$ person singular] Stems

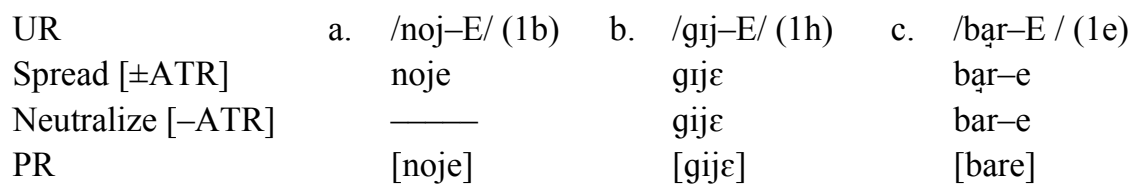

The rule ordering analysis in (4) uses three examples to illustrate that the perfective suffix acquires the $[ \pm \mathrm{ATR}]$ feature of the root, with subsequent neutralization of the $[ \pm \mathrm{ATR}]$ feature for the non-mid vowels. While one might want to analyze Bondu roots as introducing a floating $[ \pm \mathrm{ATR}]$ feature based on the perfective data, when we consider cases of suffixcontrolled harmony (Section 2.3) and suffixes that introduce a floating feature (Section 2.4), it becomes difficult to maintain a floating feature analysis of Bondu roots. See also our discussion in Section 3.2 referencing Finley (2009).

2.2 Root-controlled [ \pm ATR] Harmony: Plural Class. Further examples of root-controlled [ \pm ATR] harmony are found among a class of plurals in nouns. ${ }^{5}$ Roots with mid and high vowels in (5) demonstrate one class of nouns marked with a singular and plural suffix. ${ }^{6}$ The singular ending on these nouns is posited to be an underspecified, mid back vowel, $/-\mathrm{O} /$, which receives its [ATR] specification from its host root. The plural suffix, in the second column, is homophonous with the perfective, $/-\mathrm{E} /$, and also surfaces with the $[ \pm \mathrm{ATR}]$ value of the root via spreading.

\footnotetext{
${ }^{5}$ In Bondu, there exist at least 15 different types of plural morphemes, which seem to form semantic classes; exemplification can be found at http://dogonlanguages.org/.

${ }^{6}$ We note that low vowel roots do not appear in this class. They can appear in other classes, such as that shown in (8). We do not yet have a good explanation as to why the class in (5) lacks low vowels while the class in (8) has vowels of all heights.
} 
(5) $[ \pm$ ATR] Root-Controlled Harmony: Singular-Plural pairs

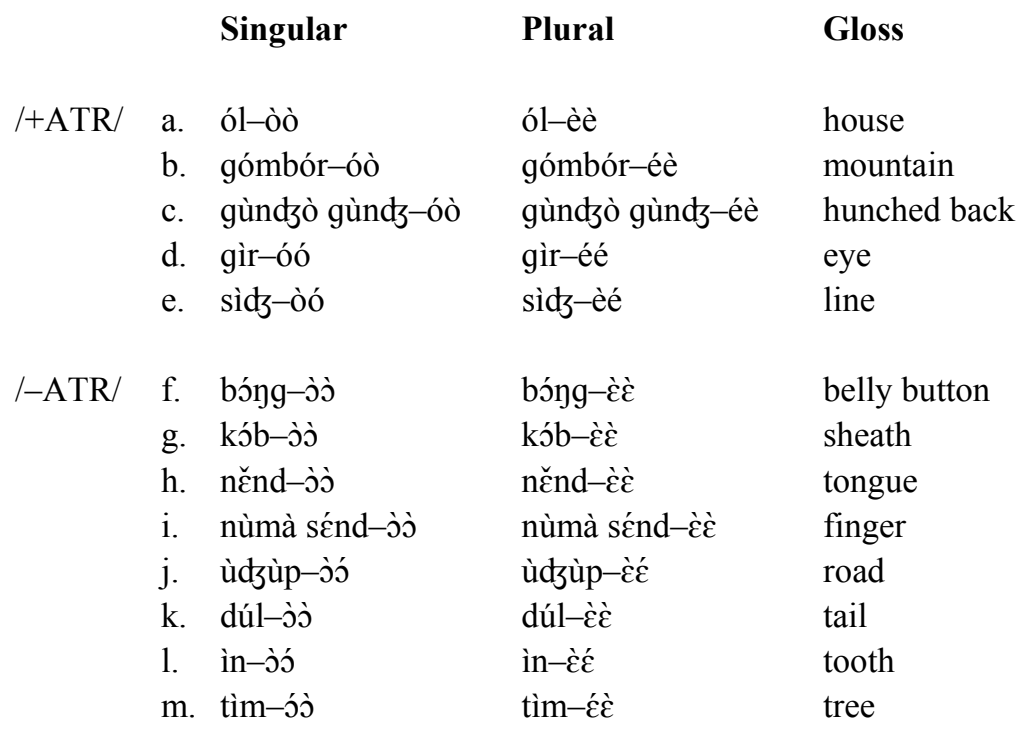

Among the singular and plural examples in (5), as with the perfective $\left[3^{\text {rd }}\right.$ person singular $]$ verbal roots in (1), both [+ATR] (5a-e) and [-ATR] (5f-m) values spread onto a suffix underspecified for the feature [ATR]. This is most clearly seen by roots with mid vowels (5ab) and (5f-h). The comparison of roots with high vowels is noteworthy. The high vowel roots in $(5 \mathrm{c}-\mathrm{e})$ trigger $[+\mathrm{ATR}]$ harmony while the high vowel roots in $(5 \mathrm{j}-\mathrm{m})$ trigger $[-\mathrm{ATR}]$ harmony. Nonetheless, the high vowels of all these roots surface with the [+ATR] value, thus suggesting that the roots in $(5 \mathrm{j}-\mathrm{m})$ are underlyingly $[-\mathrm{ATR}]$. The autosegmental analysis for (5) is essentially the same as shown in (3), so we do not repeat it. The examples in (1) and (5) are cases of root-controlled harmony. Casali (2008) notes that harmonizing suffixes are more common than suffixes that trigger harmony among [ATR] systems in Africa. Bondu-so, however, also displays suffix-controlled harmony; that is, it has dominant suffixes which spread their underlyingly specified $[ \pm \mathrm{ATR}]$ value onto a root in a feature changing manner. We consider such examples in the next section.

2.3 Suffix-controlled [ \pm ATR] Harmony. In this section we consider a number of cases of suffix-controlled harmony in which a specified $[ \pm$ ATR] feature spreads leftward from the suffix onto the root in a feature changing manner. It is shown that both [+ATR] and [-ATR] can spread from a suffix. We first consider the infinitival forms in (6) to illustrate an example 
of suffix-controlled [+ATR] harmony. The vowel of the infinitival suffix ${ }^{7}$ does not alternate with respect to the feature $[ \pm \mathrm{ATR}]$; rather the underlying [ATR] value of the suffix vowel ([+ATR] in the case of the infinitive) spreads to the root vowel in a feature-changing manner. The root vowels in (6) surface as [+ATR], regardless of their underlying feature values, save for the $[+\mathrm{LO}]$ root vowels in $(6 \mathrm{e})$ and $(6 \mathrm{j})$ which surface with the feature $[-\mathrm{ATR}]$ because of the grounded feature co-occurrence constraint $*[+\mathrm{ATR},+\mathrm{LO}]$.

(6) Suffix-controlled [+ATR] Harmony: Infinitive

\begin{tabular}{|c|c|c|c|c|}
\hline $\begin{array}{l}\text { Stem } \\
\text { /+ATR/ }\end{array}$ & Gloss & & $\begin{array}{l}\text { Stem } \\
\text { /-ATR/ }\end{array}$ & Gloss \\
\hline [némbíl-lòn] & to beg & f. & [kédz-ì̀̀)] & to cut \\
\hline [nój-ílòy] & to sleep & g. & [dòg-ílòn] & to leave \\
\hline [bí-1́lòy] & to lie down & $\mathrm{h}$. & [gí-1́lòy] & to kill \\
\hline [súg-ílòn] & to go down & i. & [dzúg-ílòn] & to recognize \\
\hline [bàr-lòn] & to help & $\mathrm{j}$. & [pág-ílòy] & to tie \\
\hline
\end{tabular}

The data items in (6) are surface forms of the stems in (1) in the infinitive. The stems in the left-hand column are underlyingly [+ATR], and those on the right are underlyingly [-ATR]. If one compares the data in (6) showing leftward spreading from the suffix to those in (1) involving rightward spreading from the root, we observe that the spreading from a specified suffix has priority over spreading from the root vowel's $[ \pm$ ATR] value; the suffix spreads to the root in a feature-changing manner. Since the verb roots in (6) are exactly the same in (1) we know the underlying [ATR] values of these data, which are shown in (2).

Another verbal suffix, the mediopassive, similarly illustrates that a suffix which is specified for the feature $[ \pm$ ATR], in this case [-ATR], spreads to the root vowel to change its underlying specification. The final vowel of the mediopassive suffix is specified for [-ATR] and is not blocked by the high, front suffix-initial vowel which is probably epenthetic. Sample forms are shown in (7). ${ }^{8}$

\footnotetext{
${ }^{7}$ We do not consider the initial [i] vowel that often appears with the infinitival suffix (e.g. all data in (6) except for (6a) and (6e)) to be underlyingly present, but rather epenthetic. It seems to predictably occur either to prevent a consonant cluster of rising sonority or after a high ([back]) vocalic element, as in the description on http://dogonlanguages.org/.

${ }^{8}$ While the majority of stems in the mediopassive show affix-dominant, [-ATR] harmony, there are exceptions such as [nèmbill-ijé] 'beg' and [sòng-ijé] 'curse'. As these examples show, the inconsistencies often involve vowel tensing before nasal clusters. There are, however, a handful of verb roots with the low vowel /a/ that seem to trigger exceptional [+ATR] harmony as with the word [dàn-ijé] 'be stuck (to something)'.
} 
(7) Mediopassive: Suffix-Controlled Harmony [-ATR]

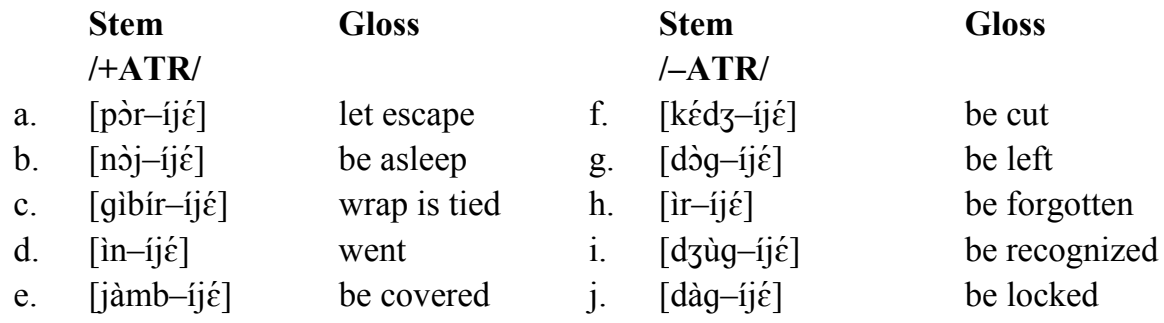

The final vowel of the mediopassive suffix, unlike the infinitival suffix, is specified as [ATR]. The suffix's [-ATR] value spreads in a feature-changing manner onto the root. This is most clearly seen in (7b) where the root vowel is underlyingly [+ATR] as evidenced by (1b). $[+\mathrm{HI}]$ root vowels $(7 \mathrm{~h}-\mathrm{i})$ and $[+\mathrm{LO}]$ root vowels $(7 \mathrm{e}, \mathrm{j})$ surface as $[+\mathrm{ATR}]$ and $[-\mathrm{ATR}]$, respectively, because of the grounded constraints * $[-\mathrm{ATR},+\mathrm{HI}], *[+\mathrm{ATR},+\mathrm{LO}]$. The data in (6) and (7) provide evidence that both [+ATR] and [-ATR] are able to spread in a featurechanging manner.

Suffix-controlled harmony is also found with nouns. We illustrate this in (8) with a class of nouns whose singular-plural pattern is somewhat different from the class shown in (5).

(8) [ $[$ ATR] Suffix-Controlled Harmony: Singular-Plural pairs

Singular

$\begin{array}{ll}\text { a. } & \text { òb-áà } \\ \text { b. } & \text { kób-áá } \\ \text { c. } & \text { bèl-áà } \\ \text { d. } & \text { cénd-àà } \\ \text { e. } & \text { nùm-àá } \\ \text { f. } & \text { kìnd-áà } \\ \text { g. } & \text { gìz-àa } \\ \text { h. } & \text { tárb-àá } \\ \text { i. } & \text { dán-àà } \\ \text { j. } & \text { kàà kár-áá } \\ \text { k. } & \text { nàà pá-áá }\end{array}$

Plural

j̀b-źc̀

kób-

bèl-ćč

cénd-ż̀े

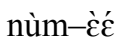

kìndz- $-\varepsilon \dot{\varepsilon}$

gìz-ćé

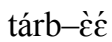

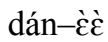

kàà kár-éć

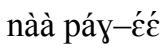

\section{Gloss}

flexible liana branch

brick mold edible leaves (cooked)

heart/liver

hand

nose

dance

hunting shelter

crown of head

armpit, underarm (where infant is grabbed)

back of leg

As can be seen in the singular column in (8), the singular roots in (8a-g) all have [+ATR] vowels and the suffix has the same low vowel quality throughout. As seen in the second column, when the plural is suffixed, the singular stem vowels shift from [+ATR] to [-ATR]. 
This is most clearly seen with mid vowel roots in $(8 \mathrm{a}-\mathrm{d})$ where there is a distinct difference in vowel quality between the singular and plural roots; there is no noticeable alternation in the high vowel pairs in (8e-g) nor for the low vowel pairs in (8h-k) due to the grounded constraint against the surfacing of $[-\mathrm{ATR},+\mathrm{HI}]$ and $[+\mathrm{ATR},+\mathrm{LO}]$ vowels, respectively. Since in $(8)$ the plural suffix for this class is always $[-\mathrm{BK},-\mathrm{HI},-\mathrm{LO},-\mathrm{ATR}]$, we analyze the suffix as being underlyingly specified for these features. Thus, this plural suffix in (8) contrasts minimally with the perfective suffix in (1), and the noun class suffixes in (5), in that it is specified for [ATR], whereas the suffixes in (1) and (5) are unspecified for any [ \pm ATR] value. In (8), the specified [-ATR] value of the plural suffix spreads onto the root changing whatever underlying [ATR] feature the root vowels may have. However, from a technical point of view, it seems that the singular suffix of this class in (8) is undeterminable as to whether it has a specific underlying [+ATR] low, back vowel where the [+ATR] feature spreads onto the root with the suffixal vowel surfacing as [-ATR], or whether the singular suffix is underlyingly a [-ATR] low, back vowel that introduces a floating [+ATR] feature. Data in Section 2.4 on the imperative provide evidence of the former.

2.4 Harmony with floating features: Imperative. In this section we present data on the Bondu-so imperative data that further substantiate our claim that initial vowels of roots are underlyingly specified for the feature [ATR]. Further, these data illustrate morphologically triggered [+ATR] harmony in the sense of Finley (2009), where a floating feature (here, [+ATR]) is introduced as part of the imperative construction. The effect of the floating feature can be seen in the observation that root vowels in the imperative surface as [+ATR] even if they are underlyingly [-ATR]. This is clear from the data in (9) below. Specifically, in $(9 \mathrm{f}-\mathrm{g})$, the root mid vowels surface as [+ATR] even though these root vowels are underlyingly [-ATR] since these same roots trigger [-ATR] harmony in the perfective as was seen in $(1 \mathrm{f}-\mathrm{g})$. Furthermore, note that the imperative $\left[2^{\text {nd }}\right.$ person singular] suffix in (9) alternates between the vowels [ó $\sim$ á]. It surfaces as [ó] if the root-initial vowel is underlyingly [+ATR, $-\mathrm{LO}$ ] in (9a-d), and as [á] if the root-initial vowel is underlying [-ATR] $(9 \mathrm{f}-\mathrm{i})$ or $[+\mathrm{LO}]$ as in $(9 \mathrm{e})$ and $(9 \mathrm{j})$.

(9) Root-Controlled $[ \pm$ ATR] Harmony with a Floating Affixal Feature: Imperative

$\begin{array}{lllll}\begin{array}{l}\text { Stem } \\ \text { /+ATR/ }\end{array} & \text { Gloss } & & \begin{array}{l}\text { Stem } \\ \text { /-ATR/ }\end{array} & \text { Gloss } \\ & & & & \\ \text { [némbíl-ó] } & \text { beg! } & \text { f. } & \text { [kédz-á] } & \text { cut! } \\ \text { [nój-ó] } & \text { sleep! } & \text { g. } & \text { [dóg-á] } & \text { leave! } \\ \text { [bíj-ó] } & \text { lie down! } & \text { h. } & \text { [gíj-á] } & \text { kill! } \\ \text { [súg-ó] } & \text { go down! } & \text { i. } & \text { [dzúg-á] } & \text { recognize! } \\ \text { [bár-á] } & \text { help! } & \text { j. } & \text { [pág-á] } & \text { tie! }\end{array}$


We propose that the imperative suffix is segmentally underlyingly a $[+\mathrm{LO}]$ vowel, but is crucially unspecified for the feature [ATR], and is represented as $/-\mathrm{A} /$. The imperative suffix must be analyzed as being unspecified for [ATR], because, as in the case of the perfective [ $3^{\text {rd }}$ person singular], the underlying $[ \pm \mathrm{ATR}]$ feature of the root-initial vowel is permitted to spread to the imperative $\left[2^{\text {nd }}\right.$ person singular] suffix. (The effect of the spreading will be seen in the vowel raising.) Subsequently, in order to account for all root vowels of the imperative surfacing as [+ATR], we posit that the imperative suffix sponsors a floating [+ATR] feature, which links to the vowel of the verb root, where it results in underlying [-ATR] root vowels surfacing as [+ATR], as most clearly seen in (9f-g). ${ }^{9}$ The process of raising the suffixal /a/ to [o] in (9a-d) may be viewed as an assimilatory process, ("parasitic harmony" (Cole \& Trigo $1988)$ ), raising the underlying [+LO] suffix vowel to $[-\mathrm{LO}]$ when preceded by a vowel that is underlyingly [+ATR, $-\mathrm{LO}]$. The process of parasitic vowel harmony in imperative $\left[2^{\text {nd }}\right.$ person] stems is represented in the autosegmental analysis in (10), where the circled [+ATR] feature is the floating feature introduced as part of the imperative construction. In (10), the left column illustrates a word whose root vowel is $[+\mathrm{ATR},-\mathrm{LO}]$ and the right column a word whose root vowel is $[-\mathrm{ATR},-\mathrm{LO}]$.

(10) Autosegmental Analysis of Harmony, Imperative [ $2^{\text {nd }}$ person singular $]$ Stems

a. Spread: The $[ \pm$ ATR $]$ value of the root-initial vowel spreads to the suffix, specifying its $[\mathrm{ATR}]$ value.
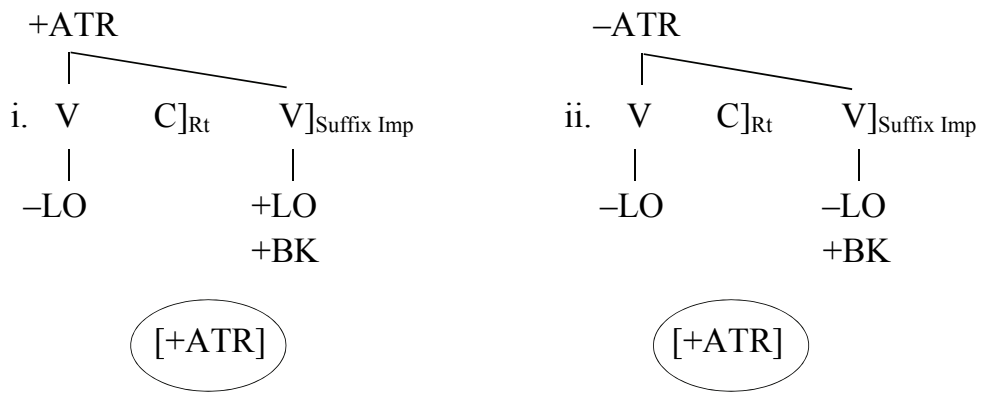

\footnotetext{
${ }^{9}$ As is shown in further examples of suffixation, the imperative [+ATR] feature is interpreted as floating rather than as a linked feature due to the fact that the suffix undergoes an alternation based on the [ATR] specification of the root. As evidenced by the infinitive suffix in (6) and the singular suffix in (8), a suffix vowel that has a specification for [ATR] does not alternate. To account for all roots in the imperative surfacing as [+ATR], we then posit the presence of the floating [+ATR] feature.
} 
b. Raise: When the preceding vowel is [+ATR, $-\mathrm{LO}]$, the suffix raises to $[\mathrm{o}]$ as in examples $(9 \mathrm{a}-\mathrm{d})$. When the preceding vowel is $[+\mathrm{LO}]$ or $[-\mathrm{ATR}]$, no raising occurs as in examples (9e-j).
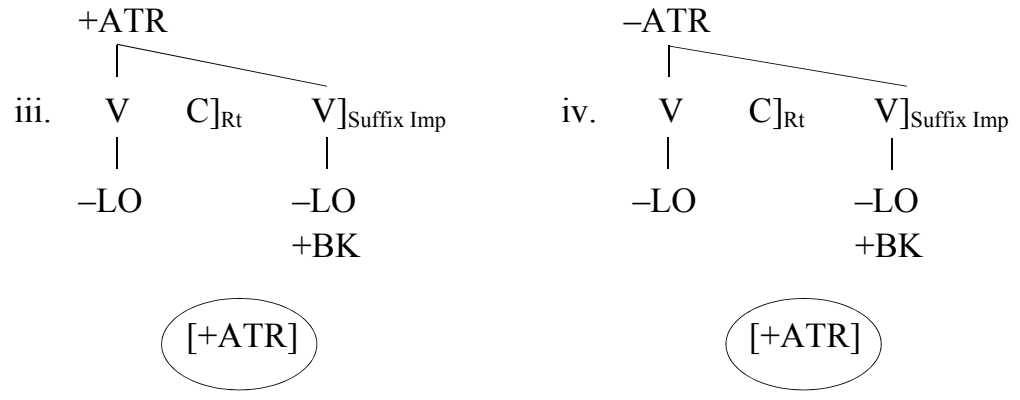

c. Link: The [+ATR] value of floating feature links to the (last) root vowel (and spreads leftward if there is more than one root vowel), causing the root vowel(s) to become $[+$ ATR].
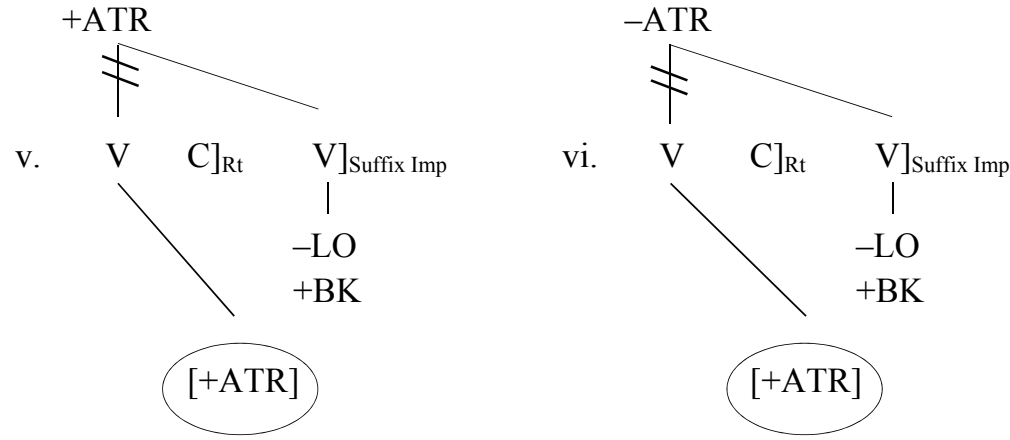

As shown above in the autosegmental analysis (10) and below in the derivational analysis (11), the spreading of the root vowel's $[ \pm \mathrm{ATR}]$ feature to the suffix occurs before the linking of the $[+\mathrm{ATR}]$ floating feature; otherwise, the raising rule of $/-\mathrm{A} /$ to $[-\mathrm{O}]$ would wrongly apply in (9f-i). 
(11) Rule-ordering Analysis of Harmony, Imperative [ $2^{\text {nd }}$ person singular] Stem

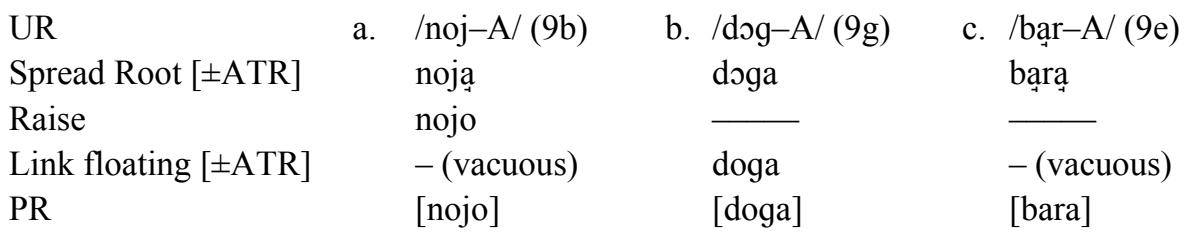

Because the imperative suffix is unspecified for [ATR], the (underlying) $[ \pm \mathrm{ATR}]$ feature of the root-initial vowel spreads to the suffix (10a). When the [+ATR] feature spreads the result is an intermediate, non-surfacing stage, in which the imperative suffix /A/ becomes [a] $([+\mathrm{ATR}])$ as seen also in (11a). The spreading of the root vowel's $[ \pm \mathrm{ATR}]$ feature to the suffix occurs before raising and linking of the [+ATR] floating feature; otherwise, the raising rule of $[-\mathrm{a}]$ to $[-\mathrm{o}]$ would wrongly apply in $(9 \mathrm{f}-\mathrm{i})$. The suffixal vowel raises from $[-\mathrm{a}]$ to $[-\mathrm{o}]$ after (underlyingly) [+ATR, $-\mathrm{LO}$ ] root vowels as in (11a). The example in (11b) does not meet the environment for raising as the root vowel is [-ATR] and in (11c) there is no raising since the root vowel is $[+\mathrm{LO}$ ] (also, in $(11 \mathrm{c})$ we are assuming that the root vowel will surface as $[-\mathrm{ATR}]$ because of the grounded constraint $*[+\mathrm{ATR},+\mathrm{LO}])$. The raising rule is crucially ordered before Link as seen in (10) and (11). To take the derivation in (11b) as an example, if Link were to apply before Raise then this would feed Raise resulting in the change of /a/ to [o] for (11b), *[dogo]. This shows that the correct ordering of Raise before Link in (10) and (11) is a counterfeeding order. Thus, the imperative data in (11) involve both [ $\left.{ }^{\mathrm{ATR}}\right]$ spreading from the root to the unspecified suffix and the linking of a floating feature introduced as part of the imperative construction.

To summarize the pattern of [ATR] harmony with imperative $\left[2^{\text {nd }}\right.$ person singular] stems, the imperative suffix is segmental, but is unspecified for the feature $[ \pm \mathrm{ATR}]$. The suffix also sponsors a $[+\mathrm{ATR}]$ floating feature. The imperative data, especially the $[-\mathrm{a}] \sim[-\mathrm{o}]$ alternation, would be more difficult to analyze if one posited a root-based floating [ATR] feature, as could be done in Yoruba, (Archangeli \& Pulleyblank 1989), rather than the underlying abstract $[ \pm$ ATR $]$ analysis posited here. Further, it provides evidence for our abstract feature analysis because the high vowels in (9h-i) are phonologically distinct from the high vowels in $(9 c-d)$. Moreover, we note that with our floating feature analysis of the imperative, the floating feature need not be realized on the morpheme (imperative) that sponsors it. This is consistent with Wolf's (2007) observation that floating features are typically not realized on the morphemes that sponsor them. Finally, as an additional observation, given that in (9) the underlying suffix $/-\mathrm{A} /$ raises to $[-\mathrm{O}]$ if the root vowel is [+ATR, $-\mathrm{LO}]$, we contend that the singular suffix $[-\mathrm{a} / \mathrm{aa}]$ in (8a) is underlyingly specified as [+ATR] since it does not alternate with [o]. That is, the [a]-to-[o] raising rule only applies to suffixes that are not specified for the feature [ATR]. Consequently, this argues against a possible alternative analysis of (9) positing that the low vowel imperative suffix is specified 
for [+ATR]. We noted that the specified low vowel suffix in (8) does not raise. It is only an unspecified suffix that undergoes raising. We will see another example of the raising of an unspecified low vowel suffix in the next section in our discussion of the imperfective.

2.5 Suffix and Root-Controlled [ \pm ATR] Harmony Combined: Imperfective. So far we have seen examples of root-controlled harmony where both [+ATR] and [-ATR] spread rightward (e.g. the perfective in (1)), suffix controlled harmony where both [+ATR] and [ATR] spread leftward in a feature-changing manner, and morphological harmony where a floating [+ATR] feature is introduced as part of the morphological construction (e.g. the imperative in (9)). The imperfective paradigm data in (12) where two suffixes are attached to the root illustrate both root-controlled and suffix-controlled harmony within the same words. The first of the suffixes in (12) denotes the imperfective aspect of the verb and is unspecified for [ATR], while the second marks person and is specified for [ATR]; specifically, the third person plural suffix is specified as [-ATR] (underlined in (12)) and the other imperfective person suffixes are [+ATR]. The root vowel in (12a) is underlyingly [-ATR] while that in $(12 b)$ is [+ATR]. Note that all non-low vowels in (12a-b) in the forms for person other than $\left[3^{\text {rd }}\right.$ plural $]$ surface with [+ATR] on the root vowels. Our focus, however, is on the $3^{\text {rd }}$ person plural forms in (12), underlined for clarity. In these forms, all vowels of the stem surface as [-ATR].

(12) Suffix and Root-Controlled Harmony: Paradigms Illustrating the Imperfective
a. Slaughter: $/ \mathrm{sem} /$
$1^{\text {st }} \mathrm{sg}$
$2^{\text {nd }} \mathrm{sg}$
$3^{\text {rd }} \mathrm{sg}$
sém-ándz-òm
$1^{\text {st }} \mathrm{pl}$
$2^{\text {nd }} \mathrm{pl}$
$\underline{3^{\text {rd }} \mathrm{pl}}$
sém-ándz-ójì
sém-ándz-è
sćm-ándz-ćè
b. Heal: /dzoy/
$1^{\text {st }} \mathrm{sg}$
$2^{\text {nd }} \mathrm{sg}$
$3^{\text {rd }} \mathrm{sg}$
dzón-óndz-òm
$1^{\text {st }} \mathrm{pl}$
dzón-óndz-ójì
[+ATR]
dzón-óndz-òò
$2^{\text {nd }} \mathrm{pl}$
dzóy-óndz-è
dzóy-óndz-ò
$\underline{3^{\text {rd }} \mathrm{pl}}$
d3ón-óndz-ćè

In analyzing the surfacing vowel qualities of the forms in (12), we note that the underlyingly [-ATR] vowel of the root in (12a) spreads its [-ATR] value to the imperfective suffix, illustrated in (13a), which, like the imperative suffix, is underlyingly specified as being [ $+\mathrm{LO}$, $+\mathrm{BK}]$, but unspecified for the feature [ATR], thereby causing it to surface as the [-ATR] variant, [a]. In (12b), the underlying [+ATR] vowel of the root spreads its [+ATR] value to the imperfective suffix; the suffix then surfaces as the [+ATR] variant [o] by the same raising 
rule that applied to the imperative in $(10 \mathrm{~b}) .{ }^{10}$ Subsequently, the $[ \pm \mathrm{ATR}]$ value of the person suffix (rightmost suffix in (12)) spreads from right to left. In the forms other than $3^{\text {rd }}$ person plural (i.e. those where the person suffix is underlyingly [+ATR]), the [+ATR] feature of the person suffix spreads leftward causing all non-low vowels in the stems in (12) to become [+ATR]. On the other hand, the $[-\mathrm{ATR}]$ value of the $\left[3^{\text {rd }}\right.$ person plural $]$ suffix (underlined in (12)) spreads from right to left, causing all vowels in these stems to become [-ATR]. In (13) we show the autosegmental analysis for the $3^{\text {rd }}$ person plural forms. On the left is a form with a $[-\mathrm{ATR}]$ root vowel while on the right is one with a $[+\mathrm{ATR}]$ root vowel.

(13) Autosegmental Analysis of Harmony with Imperfective Stems [ $3^{\text {rd }}$ person plural]

a. Spread Root: The $[ \pm \mathrm{ATR}]$ value of the root-initial vowel spreads to the imperfective suffix.

$-\mathrm{ATR}$

i. $\mathrm{V}$<smiles>C1C[12CH2]1</smiles>

$\left.\mathrm{C}]_{\mathrm{Rt}} \mathrm{V}\right]_{\text {Suffix Imp }}$

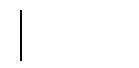

$+\mathrm{LO}$

$+\mathrm{BK}$

$\varepsilon$

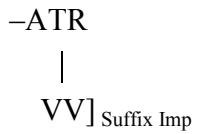

| [3rdpersonPL]

$-\mathrm{LO}$

$-\mathrm{HI}$

$-\mathrm{BK}$

$\varepsilon$

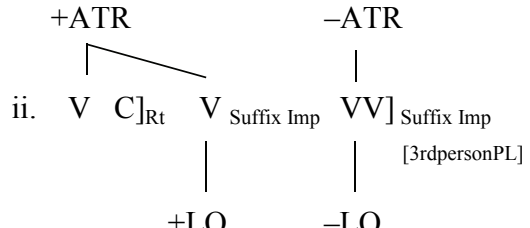

$-\mathrm{LO}$

$+\mathrm{BK} \quad-\mathrm{HI}$

$-\mathrm{BK}$

o $\quad$ a $\quad \varepsilon$

b. Raise: When the preceding root vowel is $[+\mathrm{ATR},-\mathrm{LO}]$, the imperfective suffix undergoes raising to $[\mathrm{o}],(10 \mathrm{~b} / 12 \mathrm{~b})$.
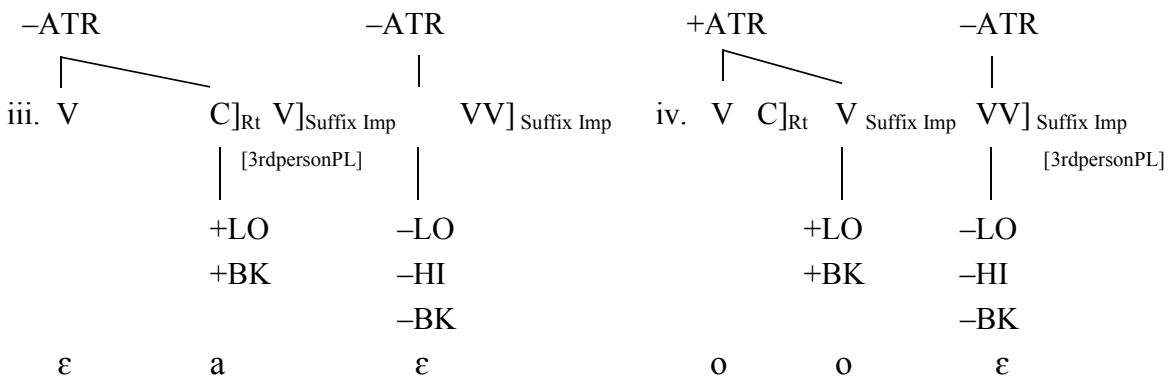

${ }^{10}$ An example of a root with a mid, front vowel is /peb/ 'whistle' surfaces as [péb-óndz-ćč in the imperfective $\left[3^{\text {rd }}\right.$ person plural], illustrating that the target is raising, not rounding, as suggested by an anonymous reviewer. 
c. Spread Suffix: [-ATR] value of imperfective $\left[3^{\text {rd }}\right.$ person plural] suffix vowel spreads leftward to imperfective stem vowels in a feature-changing manner, specifying their [ATR] values.
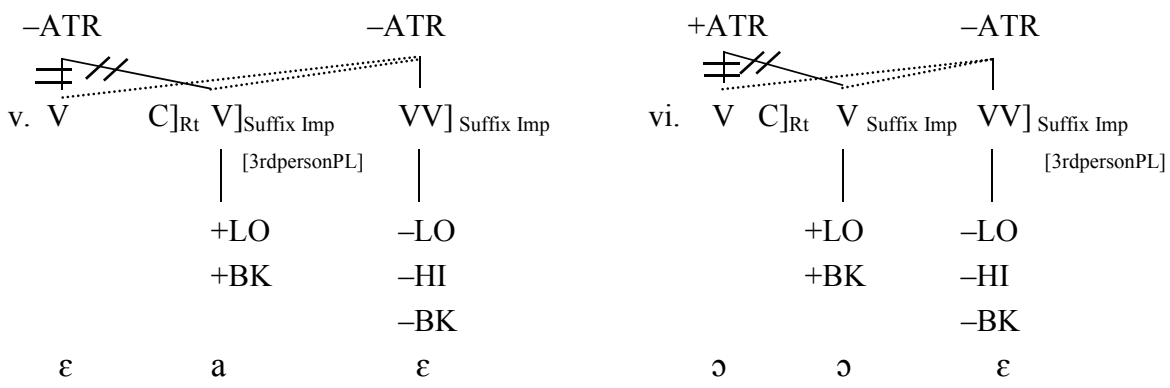

The autosegmental analysis above in (13) and the derivational analysis below (14) underscore that vowels, particularly those in suffixes (the [ $3^{\text {rd }}$ person plural] suffix here) specified for the feature $[ \pm \mathrm{ATR}]$, spread in a feature-changing manner onto roots. This must occur after the root vowel, which is specified for the feature $[ \pm A T R]$, spreads its $[ \pm A T R]$ feature to the imperfective suffix which is unspecified for $[ \pm \mathrm{ATR}]$. The ordering can be seen from the derivational analysis below in (14). ${ }^{11}$

(14) Rule-ordering Analysis of Harmony, Imperfective [3 $3^{\text {rd }}$ person pl] Stems

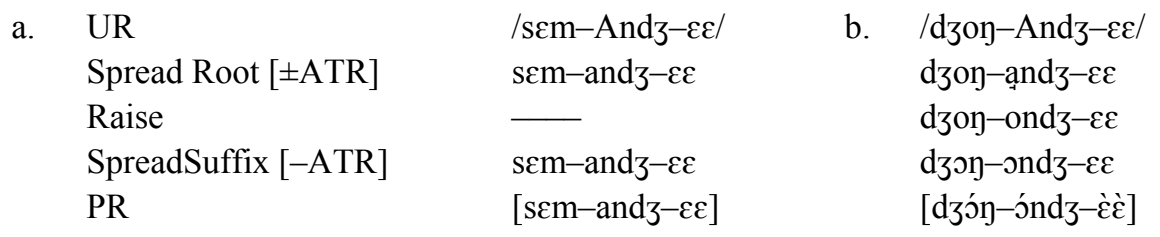

We propose that the difference between the imperative (9) and the imperfective harmony above is that the imperative is a case of root-controlled harmony with a floating feature affix, while the imperfective is a case showing both root-controlled and suffix-controlled harmony occurring in the same derivation. Moreover, depending on the person suffix of the imperfective, the spreading value of the suffix can either be [-ATR] (as seen for the $3^{\text {rd }}$ person

\footnotetext{
${ }^{11}$ Both Noske (2000) and Bakovic (2002) discuss a data item in the Nilotic language Turkana that is quite similar to the Bondu $3^{\text {rd }}$ person plural form in (12b). Bakovic (2002) offers a cyclic account of the Turkana form, which could be applied to the Bondu forms in (12), though we do not detail the cyclic analysis.
} 
plural shown in (12)) or [+ATR] as with the non- $3^{\text {rd }}$ person forms in (12). As we discuss in Section 3 , this has consequences for our understanding of the nature of $[ \pm \mathrm{ATR}]$ harmony.

2.6 Summary. Various types of vowel harmony processes were shown among noun and verb stems in the language. The perfective aspect in (1) and the noun stems in (5) display rootcontrolled $[ \pm \mathrm{ATR}]$ spreading where the $[ \pm \mathrm{ATR}]$ value of the root spreads to a suffix underspecified for [ATR]. The infinitival and mediopassive stems show examples of [+ATR] and [-ATR] spreading from a suffix specified as such as in (6) and (7) respectively. [ $\left.{ }^{ \pm A T R}\right]$ suffix spreading is also witnessed by the noun class in (8), where the singular suffix spreads [+ATR] and the plural suffix spreads [-ATR] onto the noun roots. The imperative mood in (9) not only shows the spreading of the $[ \pm$ ATR $]$ value of the root to a suffix underspecified for [ATR], but also that the suffix sponsors a floating feature which links (and spreads) onto the root, changing its [ATR] specification. Finally, combinations of both root and affixal spreading were demonstrated using examples from the imperfective in (12). The suffixes presented in this paper are summarized in the table in (15), with a complete list of suffixes found at http://dogonlanguages.org/.

(15) Summary of suffixes (parenthesized plural forms are not discussed in this article)

\begin{tabular}{|l|l|l|l|l|l|}
\hline Root-Controlled & \multicolumn{2}{|l|}{ Suffix-Controlled } \\
\hline Category & Suffix & Category & Suffix & \\
\hline & Singular & Plural & & Singular & Plural \\
\hline Perfective & E & (O) & Mediopassive & $\varepsilon$ & $($ o) \\
\hline Imperfective & O & (E) & Noun 2 (in 8) & a & $\varepsilon$ \\
\hline Noun 1 (in 5) & O & E & Infinitive & (i)lon & \\
\hline & $\begin{array}{l}\text { A (introduces a } \\
\text { floating [+ATR] } \\
\text { feature) }\end{array}$ & & & \\
\hline
\end{tabular}

We observe in general that mid vowels in either the root or the suffix are able to trigger and undergo [-ATR] harmony depending on the nature of the specification of the suffix. ${ }^{12}$ High vowels in a root may trigger [+ATR] or [-ATR] harmony. We note that there tend not to be any dominant, underlying, high vowel suffixes. A low vowel in the root may trigger either [+ATR] or [-ATR] harmony (though the latter is less common), but a low vowel in the suffix seems to only triggers [+ATR] harmony. We suspect that there are diachronic reasons for

\footnotetext{
${ }^{12}$ The one [+ATR] mid front vowel suffix found to trigger [+ATR] spreading is the verbal noun suffix $[-$ le], which we do not discuss.
} 
these observations that are beyond the scope of the present article. In the next section we consider some of the theoretical implications of our analysis.

\section{Theoretical implications}

In this section we touch on some of the theoretical implications emerging from our analysis of Bondu-so vowel harmony. First, we assume that both values of [ATR] are active in the harmony process and that underspecification is crucial. Second, since our analysis distinguishes between an [ATR] feature that is linked from one that is floating, it has relevance for recent discussion concerning floating features found in Wolf (2007) and Finley (2009). Third, our analysis raises issues for the relationship between $[ \pm \mathrm{ATR}]$ harmony and the nature of the vowel inventory as discussed by (Casali 2008). Finally, and perhaps most importantly, our analysis relates to issues of abstractness in two ways. In assuming an abstract vowel inventory, our analysis is reminiscent of some of the early analyses of vowel harmony, such as that of Vago (1973), that make use of absolute neutralization; and relatedly, there is the acoustic phonetic question as to whether perceptually identical vowels that display different harmonic behaviors are acoustically distinct. We briefly discuss each of these issues in the sections below.

3.1 Active features and underspecification. In many analyses of tongue root harmony within autosegmental phonology one feature is viewed as being active (either [+ATR] or [ATR]) and the other unspecified. For example, Archangeli \& Pulleyblank (1989) analyze Yoruba tongue root harmony with $[-\mathrm{ATR}]$ as the active feature and [+ATR] as unspecified. Within optimality-theoretic analyses of vowel harmony that forego autosegmental representation, underspecification is often not used, and, as in Bakovic (2000), specifically argued against. In such optimality-theoretic analyses, agree feature constraints that reference [ATR] play a key role in accounting for harmony with differences between root-controlled $[ \pm$ ATR $]$ harmony systems and dominant-recessive $[ \pm$ ATR $]$ harmony systems being accounted for by the ranking of the relevant constraints.

Our analysis of Bondu-so is different from both these perspectives. First, we consider both [+ATR] and [-ATR] to be active features in the harmony processes. Initial root vowels are specified as either [+ATR] or [-ATR]. As seen for example, by the perfective data in Section 2.1 and the singular-plural data in Section 2.2 the underlying [ \pm ATR] feature of a root vowel spreads to the suffix. While one may be tempted to analyze one value of [ATR] as a default value, the fact that both values can be dominant (e.g. [+ATR] of the infinitive in (6) and [-ATR] of the mediopassive in (7)) argues for the specification of both values. This suggests that neither [ATR] value acts as a default. While we maintain that both values of the [ATR] feature are active in Bondu-so harmony, underspecification of [ATR] is needed with respect to suffixes because suffixes display three types of behavior. They can undergo $[ \pm$ ATR] harmony as with the perfective suffix in (1) and the singular-plural suffixes in (5); 
they can show [+ATR] dominance as with the infinitive in (6) and the person suffixes (other than 3rd person plural) in (12), or they can display [-ATR] dominance as with the mediopassive in (7) and the $\left[3^{\text {rd }}\right.$ person plural $]$ suffix in (12).

This three-way behavior of suffixes is also found in the Nilotic language Turkana, where Noske (2000), maintains, as we do here, that alternating suffixes are unspecified for [ATR], dominant [+ATR] suffixes are specified at [+ATR] and dominant [-ATR] suffixes are specified as [-ATR]. Thus, the three-way contrast found with Bondu-so suffixes is suggestive of an underspecification analysis. Moreover, in Bondu-so, the phonology provides additional evidence for this three-way analysis of suffixes. Consider again the $\mathrm{a} \sim \mathrm{o}$ alternation pattern seen in (9) and (12). Here, a low vowel in a suffix raises to [o] when the preceding (root) vowel is $[+\mathrm{ATR},-\mathrm{LO}]$. This alternation does not pertain to any suffix with a low vowel, but only to those where the low vowel is not dominant; that is, it pertains to a low vowel that does not have an underlying [ \pm ATR] feature. This is clear by the comparison of low vowel raising in (9) and (12) with the lack of low vowel raising of the singular suffix in (8), which is underlying a low vowel but is dominant since it triggers [+ATR] harmony on the root. ${ }^{13}$ The low vowel of this suffix would be specified as [+ATR], but as we observe from the data in (8), it does not undergo raising. Thus one must distinguish between low vowel suffixes that undergo raising from those that do not. We distinguish this by underspecification. The $\mathrm{a} \sim \mathrm{o}$ alternation only affects low vowel suffixes that do not have a specification for [ATR]. Thus, we conclude that Bondu-so provides an example of an [ATR] harmony system where both features are active and underspecification is needed.

3.2 The floating feature analysis. In our analysis of Bondu-so vowel harmony, we do not make use of root-based floating features where the $[ \pm \mathrm{ATR}]$ feature is not underlyingly linked to some vowel but comes with a lexical morpheme. In some analyses of vowel harmony, such as Archangeli \& Pulleyblank (1989), lexical morphemes can sponsor a floating ([-ATR]) feature that then links to the vowels in its domain, subject to principles of autosegmental association (Goldsmith 1976) and certain language-specific constraints. We could analyze the Bondu-so data in a similar way. For example, if one considers the verb roots in (1), those in (1a-e) could be analyzed as sponsoring a floating [+ATR] feature and those in (1f-j) as sponsoring a floating [-ATR] feature. We do not pursue such an analysis, but rather maintain that the $[ \pm$ ATR $]$ feature is a property of the (initial) vowel of the root. There are both theoryinternal reasons and analytical reasons specific to Bondu-so to argue against the floating feature analysis of $[ \pm \mathrm{ATR}]$. Let us first consider the latter. In our analysis of Bondu-so, we do make use of floating features, but this has to do with the imperative data in (9). As seen by

\footnotetext{
${ }^{13}$ We note that Bakovic (2000:55 - 57) predicts the absence of low vowels being [+ATR] dominant. The singular suffix in (8) goes against Bakovic's prediction but is consistent with our abstract vowel analysis where some instances of the low vowel may be underlyingly [+ATR], although it is not perceptually distinct from its [-ATR] counterpart.
} 
the analysis in (10), the imperative suffix sponsors a floating [+ATR] feature as part of the imperative construction. Additionally, in (10c), this floating feature links to the root vowel (not the suffix vowel) thus making all root vowels [+ATR]. We eschew an analysis of the imperative where the feature [+ATR] is linked to the suffixal low vowel acting as dominant. The evidence against such an analysis comes from the singular low vowel suffix in (8). In the singular data in (8), all root vowels surface as [+ATR] just like the root vowels in the imperative in (9). However, the low vowel suffix in (8) is consistently low, not alternating. This is an indicator that it is underlyingly [+ATR]. On the other hand, the low vowel suffix in (9) alternates between a $\sim$ o where the low vowel assimilates to the $[+\mathrm{ATR},-\mathrm{LO}]$ feature of a root vowel. This then suggests that the low vowel of the suffix in (9) differs from that of (8).

On theoretical grounds, based on work such as Bakovic (2000, 2002), it is easier to maintain that dominant affixes do not undergo alternation. That is, they show a high degree of faithfulness to their underlying feature. Since the imperative morpheme in (9) displays an alternation while the singular suffix in (8) does not, the difference in behavior can be accounted for by positing that the imperative morpheme in (9) introduces a floating feature. Thus, our analysis distinguishes between the introduction of a floating feature in (9) associated with the imperative morpheme and root-based $[ \pm$ ATR] harmony as seen by the perfective in (1) and the singular-plural data in (5).

Furthermore the distinction that we make between the imperative in (9) and the perfective and singular-plural pairs in (1) and (5), respectively, is completely consistent with the important distinction developed in Finley (2009) between morphemic and phonological harmony. The latter has to do with agreement or identity of features across an output domain. This is exactly what we find in (1) and (5) where the $[ \pm \mathrm{ATR}]$ feature of the initial vowel is realized throughout the entire output domain. Thus, Bondu-so data like in (1) and (5) are just instances of phonological harmony in the sense of Finley (2009). Morphemic harmony, on the other hand, is governed by faithfulness to a specific feature that is associated with a morpheme (i.e., representationally a floating feature introduced by a specific morpheme) and aims for the realization of that feature in an output domain. Finley points out that morphemic harmony may be idiosyncratic in the sense that the floating feature may attach just to an edge vowel in its domain or to all vowels in its domain. She argues that it is only morphemic harmony that entails the introduction of a floating feature. The imperative in (9) has all the characteristics of morphemic harmony: a specific feature is associated with a specific morpheme that must be realized. Notice that in our analysis of the imperative as shown in (10c), the floating feature is not realized on the entire word domain. This is different from the case of phonological harmony shown in (4) where all vowels in the domain must agree with the harmonic feature. It is also consistent with Wolf's (2007) typological study maintaining that floating features are often not realized on the morphemes that sponsor them. Bondu-so is interesting because it witnesses both morphemic and phonological harmony. Consequently, given the work of Finley (2009) and Wolf (2007), there are theory-internal reasons not to analyze data like in (1) and (5) with floating $[ \pm$ ATR] features. 
3.3 [ \pm ATR] and vowel inventories. Casali (2008) surveys vowel inventories of languages displaying tongue root harmony and relates the nature of the inventory to the propensity to have dominant [+ATR] or [-ATR] harmony. Casali provides data to support the generalization that seven-vowel languages with tongue root harmony employ [-ATR] as the dominant harmonic feature. Specifically, languages that have the fairly common inventory $/ \mathrm{i}$ e $\varepsilon$ a $\rho$ o u/, where [ \pm ATR] contrasts only in the mid vowels, overwhelmingly have dominant [-ATR] harmony. On the other hand, he finds that languages that have the common nine vowel system /i I e $\varepsilon$ a $\rho$ o $\mho \mathrm{u} /$, with $[ \pm \mathrm{ATR}] \mathrm{mid}$ and high vowels, overwhelmingly witness dominant $[+\mathrm{ATR}]$ harmony.

It is interesting to consider Bondu-so in light of Casali's findings. On the surface, Bonduso has the seven vowel system [i e $\varepsilon$ a $\supset$ o u $]$. One might expect it to display consistent [ATR] dominance as in Yoruba. But, as shown in this paper, this is not the case for Bondu-so. However, we do not consider Bondu-so to constitute a real counterexample to Casali's results regarding seven-vowel systems. In our analysis, although Bondu-so has seven surface vowels, it has ten phonemic vowels, /i i e $\varepsilon$ a a $\rho$ o $\mho \mathrm{u} /$, with a [ $\pm \mathrm{ATR}]$ contrast for all vowel heights. We would maintain that the fact that Bondu-so does not behave like a seven-vowel system with respect to [-ATR] dominance is consistent with our abstract vowel analysis that posits a larger number of underlying vowels. We conjecture that Bondu-so in its current state is in a situation of flux going from an earlier system in which there was a distinct ten vowel phonemic system to one in which surface (or perceptual) [ \pm ATR] contrasts are being lost on high and low vowels. These vowels, nonetheless, maintain their historical behavior with respect to harmony. It may be that in another generation or two, the system of vowel harmony will be different from what we have found at the beginning of this century.

3.4 Abstractness. Abstractness issues in analyses of vowel harmony have a history that is probably as long as that of generative phonology. By abstractness, we mean the positing of segments in underlying representation that do not appear in a contrastive form on the surface in any environment. That is, abstract segments are posited phonemes that undergo absolute neutralization. In our analysis we posit $[-\mathrm{ATR},+\mathrm{HI}]$ vowel phonemes that neutralize to [+ATR] on the surface and [+ATR, $+\mathrm{LO}]$ phonemes that are at least perceptually indistinguishable from their $[-\mathrm{ATR},+\mathrm{LO}]$ counterparts. In this way, our abstract analysis is reminiscent of Vago (1973), who specifically argues for an abstract analysis of the vowel harmony systems in several Uralic and Altaic languages incorporating rules of abstract neutralization, thus arguing against Kiparsky (1968). Vago's justification for abstract analyses using absolute neutralization is essentially phonological. For example, he shows that a posited abstract feature that neutralizes is integrated into the phonology in such a way that it can show effects beyond vowel harmony.

Similarly, Kenstowicz \& Kisseberth (1979) in discussing various cases of abstract phonological analyses that make use of absolute neutralization (such as the positing of long 
high vowel phonemes in Yawelmani Yokuts though no long high vowels actually surface) conclude that such abstract analyses are possible as long as there is enough evidence for it; that is, that the abstract segment is well-integrated into the phonology of the language. In this way, we believe that the abstract vowels that we posit in our analyses of Bondu-so, specifically the $[-\mathrm{ATR},+\mathrm{HI}]$ and $[+\mathrm{ATR},+\mathrm{LO}]$ vowels that do not surface are well-integrated into the phonology. In considering data like that in (1), we observed that certain high vowels trigger [-ATR] harmony though such high vowels surface as [+ATR]. The abstract nature of these [-ATR] high vowels can be seen not only by the vowel harmony pattern they trigger but by the facts seen in (9h-i), that they block the raising of /A/-to-[o] even though they surface as [+ATR] and so should be a trigger for the rule. We know independently from the mid vowel example in (12a) that underlying [-ATR] vowels block the raising. Thus, the [-ATR] feature of the posited abstract high vowel phonemes is well-integrated into the phonology of the language. ${ }^{14}$ Similarly, with the abstract [+ATR] low vowels, not only do we see that they can trigger [+ATR] harmony as in (1e), but such low vowels can show [+ATR] dominance as a suffix as in the singular forms of (8). Consequently, we believe our abstract analysis of ten underlying vowels where there is a $[ \pm \mathrm{ATR}]$ contrast for each vowel height is well-motivated.

As a final matter regarding our abstract analysis, an important question in light of recent work by Gick et al. (2006) and Benus \& Gafos (2007) concerns the phonetics of the two low vowel phonemes that we posit for Bondu-so (/a/ and /a/). It is certainly clear to the first author who has done extensive fieldwork on Bondu-so that native speakers do not perceive a difference between low vowels that trigger [+ATR] harmony from those that trigger [-ATR] harmony. Likewise, there seems to be no perceptual phonetic difference in Bondu-so between high vowels that trigger [-ATR] harmony from their counterparts that trigger [+ATR] harmony. ${ }^{15}$

Recent studies on the phonetics of vowel harmony have shown that there may be small but consistent acoustic differences between perceptually identical vowels depending on their harmony context. For example, Gick et al. show that the low vowel in Kinande, which is typically described as being neutral to the [ATR] harmony of the language, participates in it consistently, being more phonetically retracted in [-ATR] environments than in [+ATR] environments. Similarly, Benus \& Gafos (2007) show that Hungarian high front vowels that exceptionally trigger back harmony in suffixes are, in fact, made further back than the

\footnotetext{
${ }^{14}$ Because we argue that root vowels are either specified for [+ATR] or [-ATR], Bondu-so is somewhat different from the dominant-reversal analysis of Turkana discussed by Bakovic (2000) which witnesses [+ATR] dominance from stems (roots), but with a handful of suffixes showing [-ATR] dominance. In our analysis of Bondu-so, roots can either be [+ATR] dominant or [-ATR] dominant depending on the value of the first vowel. Consequently, this is not exactly an example of Dominance Reversal.

${ }^{15}$ The results of a pilot study and acoustic measurements showing the merger of high and low vowels that trigger [+ATR] and [-ATR] harmony are available at http://dogonlanguages.org/.
} 
(perceptually indistinct) high vowels that trigger the expected front harmony. While we have not done a thorough investigation of the acoustics of Bondu-so vowels, some preliminary work seems to suggest that there may not be a consistent difference between low vowels that trigger [+ATR] harmony (represented as /a /) and those triggering [-ATR] harmony (represented as $/ \mathrm{a} /$ ). Further work would need to examine low vowels that are not triggers, but undergoers as well, for example, the initial vowel in (6j) or those low vowels that resist raising as in $(9 \mathrm{~h}-\mathrm{i})$.

Preliminary work on high vowels suggests that underlying [-ATR] high vowels have neutralized completely on the surface with their [+ATR] counterparts. Needless to say, a full investigation of the acoustics of Bondu-so vowels is beyond the scope of the current paper and will necessarily constitute a separate independent paper. However, the analysis presented in this paper enables one to examine the vowel acoustics in a phonologically informed manner.

In this section we have touched on what we consider to be the most important theoretical implications of our analysis of Bondu-so harmony. There are several implications that we have not discussed and leave for future research. One implication, as just mentioned, is whether a detailed phonetic analysis supports absolute neutralization or something like near merger (e.g., Yu 2011). Other theoretical implications of Bondu-so harmony relate to its analysis in Optimality Theory. There are many technical issues that it raises including the conception of harmony as entailing agreement features (Bakovic 2000, Krämer 2003) or alignment features (Akinlabi 1994), the apparent cyclicity of the process as illustrated by data like in (12b), and analytical issues related to opaque output forms such as (9h-i) where low vowel raising does not occur although the environment for it seems to be met on the surface. We leave a detailed optimality-theoretic analysis of Bondu-so vowel harmony for future research.

To conclude, we see the contribution of this article as being both descriptive and theoretical. In terms of description, we have provided a new set of vowel harmony data from a language that has not been previously described in the published literature. The vowel harmony system is unusual in that it witnesses both [+ATR] and [-ATR] spreading from roots and suffixes. Although this pattern may be unusual typologically, we have reason to suspect that it is common in other Dogon languages based on preliminary work. With respect to theory, we have offered an autosegmental analysis in which we argue for an abstract vowel system and a three-way contrast in the feature [ATR]. While both an abstract vowel system and a ternary contrast in a distinctive feature are theoretically controversial, our analysis has been data-driven rather that theory-driven. We leave it as a challenge as to whether the full range of vowel harmony data considered in this article can be accounted for just as insightfully without positing abstract vowels or the ternary use of [ATR]. 


\section{References}

Akinlabi, A. (1994). Alignment constraints in ATR harmony. Studies in Linguistic Sciences 24, 1-18.

Archangeli, D., \& Pulleyblank, D. (1989). Yoruba vowel harmony. Linguistic Inquiry, 20, 173-217.

Archangeli, D., \& Pulleyblank, D. (1994). Grounded Phonology. Cambridge, MA: MIT Press. 2(3), 496 - 549.

Bakovic, E. (2000). Vowel Harmony and Stem Identity. PhD dissertation, Rutgers University.

Bakovic, E. (2002). The consequences of microvariation in East Nilotic. Paper presented at Glow 2002, Amsterdam April 12.

Benus, S., \& Gafos, A. (2007). Articulatory characteristics of Hungarian transparent vowels. Journal of Phonetics 35, 271-300.

Casali, R. (2008). ATR harmony in African languages. Language and Linguistics Compass, Cole, J., \& Trigo, L. (1988). Parasitic harmony. In Smith \& Hulst (Eds.), Features, Segmental Structure and Harmony Processes (Part II) (pp. 19 - 38): Walter de Gruyter.

Finley, S. (2009). Morphemic harmony as featural correspondence. Lingua 119, 478 - 501.

Gick, B., Pulleyblank, D., Campbell, F., \& Mutaka, N. (2006). Low vowels and transparency in Kinande vowel harmony. Phonology 23, 1-20.

Goldsmith, J. (1976). Autosegmental Phonology. Bloomington, IN: Indiana University Linguistics Club.

Heath, Jeffrey (2011). A Grammar of Najamba Dogon (= Bondu-So). Retrieved December 20, 2012 from http://dogonlanguages.org/grammars.cfm.

Heath, Jeffrey (n.d.). Dogon ATR-Harmony. Retrieved December 20, 2012 from http://dogonlanguages.org/typology.cfm.

Kenstowicz, M., \& Kisseberth, C. (1979). Generative Phonology: Description and Theory. San Diego: Academic Press, Inc.

Kiparsky, P. (1968). How Abstract is Phonology. Bloomington, IN: Indiana University Linguistics Club.

Krämer, M. (2003). Vowel Harmony and Correspondence Theory. Walter de Gruyter.

Noske, M. (2000). [ATR] harmony in Turkana: A case of Faith Suffix $\gg>$ Faith Root. Natural Language and Linguistic Theory 18, 771-812.

Vago, R. (1973). Vowel harmony systems in Uralic and Altaic languages. Language 49, 579605.

Wolf, M. (2007). For an autosegmental theory of mutation. In L. Bateman, M. O'Keefe, E. Reilly \& A. Werle (Eds.), University of Massachusetts Occasional Papers in Linguistics 32: Papers in Optimality Theory III (pp. 315-404). Amherst: GLSA. 
Yu, A. (2011). Mergers and neutralization. In M. van Oostendorp, C. Ewen, E. Hume \& K. Rice (Eds.), The Blackwell Companion to Phonology (pp. 1892-1918). Oxford: WileyBlackwell.

Abbie Hantgan

ahantgan@umail.iu.edu

Stuart Davis

davis@indiana.edu
Accepted :

Revisions: 